\title{
Pregnancy and multiple sclerosis: a longitudinal study of 125 remittent patients
}

\author{
E Roullet, M-H Verdier-Taillefer, P Amarenco, G Gharbi, A Alperovitch, R Marteau
}

\begin{abstract}
The relationship between pregnancy and multiple sclerosis (MS) was assessed in a clinic-based, prospectively followed, population of 125 patients with a remittent onset of MS who had been followed for a mean (SD) of $10.3(0.1)$ years. Thirty three women had a total of 49 pregnancies of which 32 had been full term and 17 terminated. There was a three-fold increase in the relapse rate per year during the first three months following delivery, compared with the baseline period of the same patients $[1.62(0.38)$ vs $0.51(0.08) p=0.05]$. During pregnancy itself, the relapse-rate was not different from baseline. The overall relapse rate of the pregnancy group was lower than that of a control group without pregnancies after MS onset, but similar to that of patients who had children after MS onset, but no pregnancy during follow up. Pregnancy did not lead to increased disability. These results confirm that post partum increase in relapse rate is the main event related to pregnancy in MS and underline the difficulties of undertaking prospective studies in this field.
\end{abstract}

$(\mp$ Neurol Neurosurg Psychiatry 1993;56:1062-1065)

A number of retrospective studies have evaluated the impact of pregnancy on the course of multiple sclerosis (MS). ${ }^{1-13}$ Overall they report an increase of the relapse-rate during the post-partum period compared to pregnancy itself or to non-pregnancy periods in the same patients, and a lower relapse-rate during pregnancy itself. ${ }^{810}$ Three $^{1}$ studies $^{7912}$ evaluated disability in relation to pregnancy, but only one of them considered prognostic factors such as duration of MS and age at onset. ${ }^{12}$ Prematurely-terminated pregnancies have not been assessed in these studies. The retrospective design of these studies implies obvious limitations as to their conclusions, because recollection biases can alter the number and the temporal location of events, and may lead to false associations. The only prospective study published to date ${ }^{14}$ concerns only a small number of patients. We evaluated the effects of all pregnancies on different parameters of the long-term evolution of MS in our clinic-based, prospectively-followed MS population and now report our results in the group of patients with the remit- tent form of MS. Our objectives were: 1) to describe the course of MS during pregnancies and the post-partum period; and 2) to determine if pregnancies could alter the long-term prognosis of disease in these patients. We compared two groups of patients, with and without pregnancy during follow up, and analysed the relationship between the course of MS and the occurrence of pregnancies in these patients.

\section{Methods}

PATIENTS AND COLLECTION OF DATA

Since 1967, MS patients in our clinic have been evaluated in a standard way. At the first visit, age at MS onset, number of children and date of pregnancies are collected retrospectively. Clinical assessment is made by a group of 3 neurologists who use uniform criteria for diagnosis, events and disability. Diagnosis was based on Schumacher's criteria $^{15}$ before 1983 and on Poser's ${ }^{16}$ thereafter. Events and disability are recorded prospectively at each visit. All patients are examined at least once a year and more frequently if worse; they are instructed to phone at each worsening of symptoms, and are then examined if judged necessary. The occurrence of new symptoms or the noticeable aggravation of old symptoms, lasting more than 24 hours, with or without objective changes on clinical examination are considered as a relapse, whereas isolated paroxysmal symptoms such as Lhermitte's sign or trigeminal neuralgia are not. Progression is the progressive worsening of symptoms and signs over a period of six months or longer. The overall evolution of MS is thus of 4 subtypes: remittent, remittent-progressive, progressive from onset or unclassified. When a patient has entered a progressive phase, he remains classified as progressive, even if relapses occur later; relapses are not scored during the progressive phase because even prospective data are judged unreliable in this setting. Permanent disability is assessed through Kurtzke's Expanded Disability Status Scale (EDSS, ${ }^{17}$ ). From 1967-84, disability had been assessed through our own disability scale $^{18}$ and was then converted to EDSS. In female patients, the occurrence and outcome of all pregnancies were recorded, allowing precise location of the distribution of relapses during pregnancy and postpartum. The end of the study was 1 September 1989 or the last visit before that date. Disability and evolutive type were assessed and the total number of relapses 
during the remittent phase of MS was tabulated.

\section{SELECTION OF PATIENTS}

At the end of the study, 316 female patients with a definite diagnosis of MS had had one or more visits to the clinic. Among the patients who had the remittent form of MS at first visit and who had been followed one year or more, 33 had at least one pregnancy during follow up (pregnancy group), and 92 were aged 40 or less at onset of MS and had no pregnancies during follow up. This latter group was further divided in two groups according to the date of pregnancies compared with that of onset of MS: 17 patients had pregnancies after MS onset, but before the follow up period (control group 1), and 75 patients had no pregnancies after MS onset (control group 2). The main characteristics of the 3 groups of patients are shown in table 1 .

\section{STATISTICAL ANALYSIS}

The relapse-rate per year was calculated for each woman as the ratio of the number of relapses over the duration of the remittent phase during which they occurred. We studied the women in the pregnancy group first. The relapse-rates per year related to each 3 month period of pregnancy and postpartum were compared with that of the same women, calculated for the period without any pregnancy and excluding the 6 months-postpartum periods (baseline period). We then compared the pregnancy and control groups for relapse-rate and EDSS, both at entry and at the end of follow up. The means of studied variables were adjusted on prognostic factors (age at onset and duration of MS) by covariance analysis using SAS (Statistical Analysis Package).

\section{Results}

PREGNANCY GROUP

A total of 49 pregnancies were observed during follow up. Twenty one women had one pregnancy, 8 had two and 4 had three pregnancies. Thirty two pregnancies were fullterm pregnancies and 17 spontaneous or voluntary abortions; seven of these were the only pregnancy in 6 women. Deliveries of full-term pregnancies were uneventful, except

Table 1 Comparison of initial data in 3 groups of remittent MS patients

\begin{tabular}{|c|c|c|c|c|}
\hline & $\begin{array}{l}\text { Women with } \\
\text { pregnancies } \\
\text { during follow up } \\
\text { (Pregnancy group) } \\
n=33\end{array}$ & $\begin{array}{l}\text { Women with } \\
\text { pregnancies after } \\
M S \text { onset } \\
\text { (Control group 1) } \\
n=17\end{array}$ & $\begin{array}{l}\text { Women without } \\
\text { pregnancies after } \\
\text { MS onset } \\
\text { (Control group 2) } \\
n=75\end{array}$ & $p$ \\
\hline $\begin{array}{l}\text { Age (years) } \\
\text { mean(SEM) }\end{array}$ & $38.5(1.5)$ & $43 \cdot 1(2 \cdot 1)$ & $39 \cdot 4(1 \cdot 2$ & ns \\
\hline $\begin{array}{l}\text { Age at onset (years) } \\
\text { mean (SEM) }\end{array}$ & $23.9(0.7)$ & $23.9(1.2)$ & $26 \cdot 7(0.7)$ & 0.03 \\
\hline $\begin{array}{l}\text { Duration of MS at } \\
\text { entry (years) } \\
\text { mean (SEM) }\end{array}$ & $2.6(0.5)$ & $7 \cdot 3(1 \cdot 1)$ & $2.8(0.4)$ & 0.001 \\
\hline $\begin{array}{l}\text { Duration of } \\
\text { remittent } \\
\text { follow up (years) } \\
\text { mean (SEM) }\end{array}$ & $10 \cdot 5(1 \cdot 1)$ & $10 \cdot 0(1 \cdot 7)$ & $8 \cdot 9(0.8)$ & ns \\
\hline $\begin{array}{l}\text { EDSS at entry } \\
\text { mean (SEM) }\end{array}$ & $2 \cdot 15(0 \cdot 22)$ & $3.44(0.50)$ & $2.51(0.17)$ & 0.02 \\
\hline
\end{tabular}

in the only twin pregnancy in which placenta praevia caused the death of one twin. One other child had multiple malformations. The deliveries and children of the three patients treated by azathioprine during full-term pregnancies were normal. Premature termination of pregnancy before 3 months was caused by spontaneous abortion in 4 cases and was a medical decision in 13 cases. MS was the main or the only factor of the decision in 11 of these latter cases: 5 of them were experiencing a relapse, 3 were receiving azathioprine, and although MS was not progressive, therapeutic abortion was undertaken in 3 other cases. Other causes of premature termination of pregnancy were ectopic and molar pregnancies (one each). The average follow up after termination of the last pregnancy was 100.3 months (range: 6 to 264).

The crude relapse-rate during follow up in the pregnancy group as a whole was 0.59 (SEM 0.07). One hundred and eighty seven relapses occurred during follow up in this group; 25 of them occurred during pregnancy and 19 during postpartum periods; only one woman in the pregnancy group had no relapse during follow up. Thirteen patients had all relapses outside the pregnancy and postpartum periods. Nineteen relapses occurred during the 32 full-term pregnancies, and 17 during the corresponding postpartum periods; thus $53 \%$ of full-term pregnancies were followed by a relapse. Six relapses occurred during prematurely terminated pregnancies and 2 during the corresponding postpartum periods.

The figure shows relapse-rates for different periods of follow up for full-term pregnancies. Relapse-rate was 0.51 (SEM 0.08) during baseline; during the 3 trimesters of pregnancy, relapse-rates were quite similar $[0.61$ SEM 0.27 to 0.84 SEM 0.32 ] and not dif-

Figure Relapse rate in women with pregnancies during follow up.

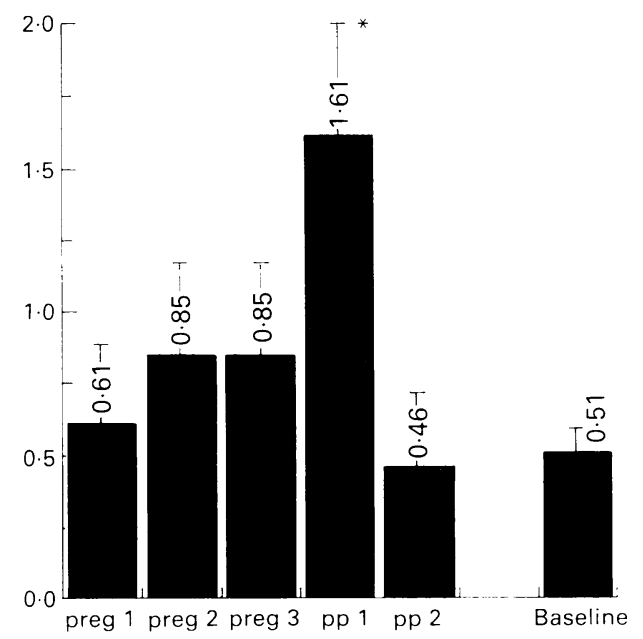

Relapse-rate: ratio of the number of relapses over the duration of periods (in years); preg 1, 2 and 3: first, second and third trimesters of full-term pregnancies; $p p 1$ and 2: first and second trimesters following delivery; baseline: period without any pregnancy (and excluding corresponding postpartum periods).

*: significant difference from baseline. 
ferent from baseline. During the first 3 months following delivery of full-term pregnancies, there was a sharp increase of relapserate (1.62 SEM 0.38) significantly different from baseline $(p=0.05)$. During the following 3 months, relapse-rate was again not different from baseline (0.46 SEM $0.26 \mathrm{NS})$. During prematurely-terminated pregnancies, relapse-rate was excessively high $(2 \cdot 10$ SEM $0 \cdot 70$ ) and significantly different from the baseline value $(p=0.05)$.

The severity of relapses was variable. Relapses occurring during pregnancy were generally mild or moderate (24/25) and left no or minimal residual disability (only 4 patients had an increase in EDSS of 1 point or more). One patient had a severe multifocal relapse (EDSS: 6 ) during the first trimester of pregnancy, which cleared completely without steroids. During the postpartum period, relapses tended to be more severe and 8 (out of 19) resulted in an increment of EDSS of 1 point or more. One patient had onset of severe bilateral optic neuritis and complete paraplegia 24 hours after delivery, with slow improvement and marked residual disability (EDSS: $4 \cdot 0$ ); five years later she had another pregnancy, and again experienced early relapse ( 2 weeks after delivery), which cleared without further sequelae.

Eight patients entered the progressive phase of MS during follow up, an average of 91.1 months after the last pregnancy (range 67 to 127). During follow up, EDSS was unchanged in 13 patients; it deteriorated by one point in 5 patients, by 2 in 7 and by 3 or more points in eight patients.

COMPARISON OF PREGNANCY AND CONTROL GROUPS As shown in table 1, patients who had no pregnancies after MS onset (control group 2) were older at onset of MS than patients belonging to the other groups. Duration of MS at entry in the study was longer and EDSS at entry higher in control group 1 than in the other groups $(p=0.02)$. Duration of follow up in the remittent phase was not different in the three groups. Comparisons of the clinical variables are summarised in table 2. After adjusting for age at onset and duration of MS, the relapse-rate differed significantly (at the $p=0.07$ level) between the three groups. The relapse rate of women without any children after MS onset was higher than that of the pregnancy group. The

Table 2 Comparison of evolutive data between 3 groups of remittent MS patients

\begin{tabular}{lllll}
\hline & $\begin{array}{l}\text { Women with } \\
\text { pregnancies } \\
\text { during follow up } \\
\text { (Pregnancy group) } \\
n=33\end{array}$ & $\begin{array}{l}\text { Women with } \\
\text { pregnancies after } \\
\text { MS onset } \\
\text { (Control group 1) } \\
n=17\end{array}$ & $\begin{array}{l}\text { Women without } \\
\text { pregnancies after } \\
\text { MS onset } \\
\text { (Control group 2) } \\
n=75\end{array}$ & p \\
\hline $\begin{array}{l}\text { Relapse Rate/years } \\
\text { mean (SEM) }\end{array}$ & $0.54(0.13)$ & $0.55(0.20)$ & $0.86(0.09)$ & 0.07 \\
$\begin{array}{l}\text { Variation of EDSS } \\
\text { mean (SEM) }\end{array}$ & $1.57(0.35)$ & $0.82(0.50)$ & $1.32(0.24)$ & ns \\
$\begin{array}{l}\text { Transition to progressive } \\
\text { form (per cent) }\end{array}$ & $24 \%$ & $23 \%$ & $17 \%$ & $\mathrm{~ns}$
\end{tabular}

$\$$ Relapse rate/year: per each woman, ratio of number of relapses over duration of remittent phase (in years).

${ }_{\star}^{\star}$ Adjusted on age at MS onset and on duration of disease at entry in the study.

$\star \star$ Adjusted on age at MS onset and on duration of the disease at the end of follow up. variation in EDSS during follow up (either mean EDSS or repartition of patients according to increments in EDSS) and the percentage of patients who entered the progressive phase of MS during follow up were not different between the three groups.

\section{Discussion}

We included in this study all MS patients registered at our clinic during a 22 year period; $33 \%$ of them were seen within 2 years of onset; the age and disability distribution (data not shown) of this clinic-based population are similar to those of geographically-based populations, ${ }^{12}$ and we believe that the prospective follow up of this population gives valuable information on the natural history of MS in relation to pregnancy.

When remittent MS patients were used as their own controls, we could confirm the stepwise increase of relapse-rate during postpartum already shown in all earlier retrospective studies and in the only prospective study published to date. ${ }^{14}$ In that latter study, 6 out of $8(75 \%)$ patients had a relapse during the first 7 weeks of postpartum; the corresponding figure in our study was $43 \%$. The postpartum increase in relapse-rate is apparent during the first 3 months after delivery, but during the following 3 months relapse-rate turns back to its baseline value; the transient nature of this phenomenon was evident in some but not all retrospective studies.

Pregnancy itself was analysed in three retrospective studies ${ }^{81013}$ which showed a reduction of the frequency of relapse during pregnancy either in the first and the second ${ }^{10}$ or the third trimester. ${ }^{813}$ Calculation of relapse-rate in one of these studies ${ }^{8}$ was hampered by the arbitrary attribution of undated relapses to the postpartum or pregnancy periods. Although relapse-rates were slightly higher during pregnancy than during baseline in our study, we found no significant differences between any trimester of full-term pregnancies and the baseline, non-pregnancyassociated period. This difference with earlier studies may be attributed to the prospective collection of data in our study. This result contrasts with the significant, three-fold, increase of relapse-rate during the postpartum period, and indicates that the magnitude of any difference between pregnancy itself and baseline on this particular point is probably small. In that respect, MS could differ from other putative autoimmune disease in which remission is thought to result from immunosuppression induced by pregnancy. ${ }^{19}$

Despite the increase of relapse-rate observed during the first 3 months following delivery, the overall relapse-rate during follow up in the pregnancy-group was not significantly different from that of the control groups without pregnancy during follow up. Interestingly, the relapse-rate of patients who had children after MS onset, either during follow up or before that period (control group 1), was lower than the relapse-rate of the patients who had no pregnancy after MS 
onset. This result could be interpreted as indicating a protective effect due to pregnancy. Although we did not collect data on the reasons that led patients to choose to start a pregnancy, an alternative and more probable explanation would be that only patients with unfrequent relapses chose to have children, thus explaining the apparent differences in relapse-rate between groups. Whether pregnancies can reduce relapse-rate in some MS patients should be assessed in prospective studies in which: 1) patients would receive baseline information before deciding to start a pregnancy; and 2) the determinants of their choice would be collected before onset of pregnancy.

A high relapse rate was observed during prematurely-terminated pregnancies, but no firm conclusion can be drawn from this result. The number of events is small, and in fact termination of pregnancy was decided because of the relapse in some of these patients.

Three retrospective studies evaluated longterm disability in relation to pregnancy ${ }^{7912}$; no association was found between the number of children or timing of pregnancies and disability. During the prospective follow up of our remittent patients, increasing disability was not related to pregnancies, even when prognostic variables such as age at onset and duration of MS were taken into account. In the other study in which these variables were assessed, similar results were found. ${ }^{12}$ Few remittent patients become progressive or experience a significant increase in disability during the first years of MS, however. ${ }^{20}$ Obtaining significant prospective data on disability in relation to pregnancy clearly needs very long follow up periods, which may prove unrealistic.

Our study did not address the mechanisms involved in the postpartum increase of relapse-rate which is the most consistent finding, common to all retrospective and prospective studies. Postpartum period, stressful events $^{21}$ and viral infections ${ }^{22}$ are the only clear triggers of exacerbations in MS. The nonspecific activation of the immune system which occurs during viral infection through production of cytokines such as gamma-interferon has been advocated as a pathogenetic mechanism in infection-induced relapses. ${ }^{23}$ Although alterations of immune parameters have been described during normal pregnancy ${ }^{24}$ their magnitude is low and their clinical significance outside the maintenance of pregnancy itself may be poor. ${ }^{25}$ Hormonal factors affect the course of experimental allergic encephalomyelitis, the animal model of MS. ${ }^{26-28}$ Whether the increase in relapse-rate is related to the drop of female hormones after parturition, to the secretion of neurotransmitters and hormones such as prolactin, ${ }^{29}$ or to more subtle interferences between hormonal and immune networks ${ }^{30}$ remains to be determined. Future studies on pregnancy and MS might concentrate on the postpartum period.

1 Millar JHD, Allison RS, Cheeseman EA, Merrett J. Pregnancy as a factor influencing relapse in dissemiPregnancy as a factor influencing re

2 Millar JHD. The influence of pregnancy on disseminated sclerosis. Proc Roy Soc Med 1961;54:4-7.

3 Schapira K, Poskanzer DC, Newell DJ, Miller H. Marriage, pregnancy and multiple sclerosis. Brain 1966; 89:419-28.

4 Leibowitz U, Antonovsky A, Kats R, Alter M. Does pregnancy increase the risk of multiple sclerosis? $\mathcal{F}$ Neurol Neurosurg Psychiatry, 1967;30:354-7.

5 Mc Alpine D, Lumsden CE, Acheson ED. Multiple Sclerosis: a reappraisal. Edinburgh: Churchill Livingstone, 1972.

6 Ghezzi A, Caputo D. Pregnancy; a factor influencing the course of multiple sclerosis. Eur Neurol 1981;20:115-7.

7 Poser S, Poser W. Multiple sclerosis and gestation. Neurology 1983;33:1422-7.

8 Korn-Lubetzki I, Kahana E, Cooper G, Abramsky O. Activity of multiple sclerosis during pregnancy and puerperium. Ann Neurol 1984;16:229-31.

Thompson DS, Nelson L, Burns A, Burks JS, Franklin GM. The effects of pregnancy on multiple sclerosis: a retrospective study. Neurology 1986;36:1097-9.

10 Frith JA, Mc Leod JG. Pregnancy and multiple sclerosis. $f$ Neurol Neurosurg Psychiatry 1988;51:495-8.

11 Nelson L, Franklin GM. Risk of multiple sclerosis exacerbation during pregnancy and breast-feeding. $\mathscr{F} A M A$ 1988;259:3441-3.

12 Weinshenker BG, Hader W, Carriere, Baskerville J, Ebers GC. The influence of pregnancy on disability from multiple sclerosis: a population-based study in Middlesex tiple sclerosis: a population-based study in

13 Bernardi S, Grasso MG, Bertolini R, Orzi F, Fieschi C. The influence of pregnancy on relapses in multiple scleThe influence of pregnancy on relapses in multiple scle-

14 Birk K, Ford C, Smeltzer S, Ryan D, Miller R, Rudick RA. The clinical course of multiple sclerosis during pregnancy and the puerperium. Arch Neurol 1990;47: 738-42.

15 Schumacher G, Beebe F, Kibler R, et al. Problems in experimental trials in multiple sclerosis: report by the panel on the evaluation of experimental trials of therapy in multiple sclerosis. Ann N Y Acad Sci 1965;122: 552-68.

16 Poser CM, Paty D, Scheinberg L, et al. New diagnostic criteria for Multiple Sclerosis: guidelines for research protocols. Ann Neurol 1983;13:227-31.

17 Lhermitte F, Marteau R, Loridan M. Functional disability rating in multiple sclerosis. Acta Neurol Scand 1974; 70(suppl 101):126-8

18 Kurtzke JF. Rating neurological impairment in multiple sclerosis: an expanded disability status scale (EDSS). Neurology 1983;33:1444-52.

19 Holmdahl R. Estrogen exaggerates lupus but suppresses T-cell-dependent auto-immune diseases. $\mathcal{F}$ Autoimmum 1989;2:651-6.

20 Weinshenker BG, Bass B, Rice GPA, et al. The natural history of multiple sclerosis: a geographically-based study. 2. Clinical course and disability. Brain 1987;112: 133-146.

21 Franklin GM, Nelson LM, Heaton RK, Burks JS, Thompson DS. Stress and its relationship to acute exacerbations in multiple sclerosis. $\mathcal{f}$ Neurol Rehabil 1988; erbations in

22 Sibley WA, Bamford CR, Clark K. Clinical viral infections and multiple sclerosis. Lancet 1985;i:1313-15.

23 Waksman BH, Reingold SC. Viral etiology of multiple sclerosis: where does the truth lie? Trends Neuro $\mathrm{Sc}$ 1986;9:388-91

24 Sridama V, Pacini F, Yang S L, et al. Decreased levels of helper T-cells: a possible cause of immunodeficiency in pregnancy. N Engl f Med 1982;307:352-6.

25 Szekeres-Bartho J, Varga $\mathbf{P}$, Kinsky $R$, Kapovic $M$, Chaouat G. Progesterone dependent immunomodulation during pregnancy. In: Chaouat G, Mowbray J, eds, Cellular and molecular biology of the maternofoeta relationship. Colloque INSERM: John Libbey Eurotext, 1991:309-16.

26 Birk K, Rudick RA. Pregnancy and multiple sclerosis. Arch Neurol 1986;43:719-26.

27 Keith AB. Effects of pregnancy on experimental allergic encephalomyelitis in guinea-pigs and rats. $¥$ Neurol $S c i$ 1978;38:317-25.

28 Abramsky $\mathrm{O}$, Brenner $\mathrm{T}$, Mizrachi R, et al. Alpha-foeto protein suppresses experimental allergic encephalomyelitis. $\mathscr{f}$ Immunol 1982;2:1-7.

29 Riskind PN, Massacesi L, Doolittle T, Hauser SL. The role of proclactin in autoimmune demyelination: suppression of experimental allergic encephalomyelitis by bromocriptine. Ann Neurol 1991;29:542-7.

30 Weigent DA, Carr DJ, Blalock JE. Bidirectional communication between the neuroendocrine and immune systems: common hormones and hormone receptors. Ann NY Acad Sci 1990;579:17-27. 